\title{
Can laparoscopic appendectomy be safely performed by surgeons who are less experienced in intra-abdominal knot-tying?
}

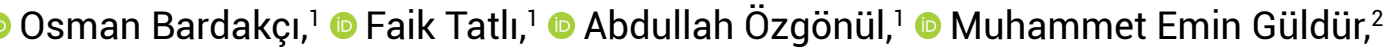

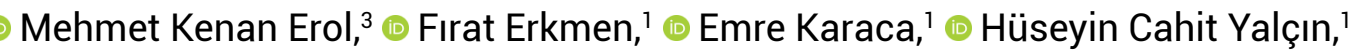 \\ Mehmet Yılmaz, ${ }^{1}$ 이 Ali Uzunköy \\ 'Department of General Surgery, Harran University Faculty of Medicine, Şanlıurfa, Turkey \\ ${ }^{2}$ Department of Pathology, Harran University Faculty of Medicine, Şanlıurfa, Turkey \\ ${ }^{3}$ Department of Anesthesiology and Reanimation, Harran University Faculty of Medicine, Şanlıurfa, Turkey
}

\begin{abstract}
Introduction: The aim of this study was to compare the handmade sailor's knot method with the intracorporeal knot method used to close the appendix stump.

Materials and Methods: The files of 47 patients who were operated on for acute appendicitis between January 2017 and January 2019 were analyzed retrospectively. The patient records were analyzed in terms of age, gender, type of laparoscopic surgery, length of hospital stay, and postoperative complications. The patients were divided into 2 groups: patients ligated with the sailor's knot method and a prepared loop (Group 1) and intracorporeally ligated patients (Group 2).

Results: Of the 47 patients included in the study, 24 were male (51\%) and 23 were female (49\%). In Group 1, $15(55.5 \%)$ patients were male and $12(44.5 \%)$ patients were female. In Group 2, there were $9(45 \%)$ male patients and 11 (55\%) female patients. The mean length of hospitalization of the patients in Group 1 was $3 \pm 1.68$ days, while it was $2.95 \pm 1.13$ days in Group 2 . The duration of surgery was $73.70 \pm 31.76$ minutes in Group 1, while it was $70.75 \pm 27.25$ minutes in Group 2 . There was no statistically significant difference between the 2 groups in terms of the length of hospitalization or the duration of surgery.

Conclusion: A handmade sailor' knot is an easy, reliable, and cost-effective method to close the appendix stump in patients undergoing laparoscopic appendectomy. The technique can be used safely when intracorporeal knot-tying or suturing cannot be performed.
\end{abstract}

Keywords: Acute appendicitis; laparoscopic appendectomy; sailor's knot.

\section{Introduction}

Acute appendicitis (AA) is one of the most common emergency surgical pathologies, with a lifetime incidence re- ported as $9 \% .{ }^{[1]}$ Appendectomy was first described by Mc Burney in 1894 and became the gold standard in the treatment of acute appendicitis. ${ }^{[2]}$ Laparoscopic appendectomy 
(LA) was first performed by Kurt Semm, a German gynecologist, in 1983 with advances in the field of laparoscopy. [3] Since then, the use of laparoscopy in the treatment of AA has increased. In a study conducted in Germany, LA was shown to increase from $47 \%$ to $86 \%$ between 2005 and 2009. ${ }^{[4]}$

Patients have advantages such as less postoperative pain, faster recovery and less hospital stay compared to open appendectomy. However, this method has disadvantages such as longer duration of operation compared to open appendectomy, increased risk of intraabdominal abscess and increased cost.

The most important stage for LA is the closure of the appendix stump. Different methods were used to close the appendix stump. Many methods such as stapler, endoloop titanium clip, hem-o-lock clip, and intraabdominal knot-tying are used..$^{[5]}$

In this study, it was aimed to compare the hand-made sailor's knot method with the intracorporeal knot method used in closing the appendix stump.

\section{Materials and Methods}

\section{Study Design and Population}

The files of 47 patients who were operated for AA between January 2017 and January 2019 were analyzed retrospectively. The patients were examined in terms of age, gender, type of knotting, length of hospital stay and postoperative complications. The patients were divided into two groups as patients ligated with loop prepare with the sailor's knot method (Group 1) and intracorporeally ligated patients (Group 2) for the closure of appendix during surgery.

\section{Technique}

We create the loop after fixing the $2 / 0$ vicryl with our $4^{\text {th }}$ and $5^{\text {th }}$ fingers in the palm of our hand, we move it around our index finger starting from the outside of our thumb and rotate it inward when it comes on the outside of our thumb and turn 4 or 5 times around the 2 ropes and then move it from top to bottom from the gap near our thumb and remove our thumb from inside of it. Since the end knot in our palm will be narrowed and close the appendix stump, the other long and fixed end is cut in a way to be short (Fig. 1). In Group 2; The stump was closed with intracorporeal knot.

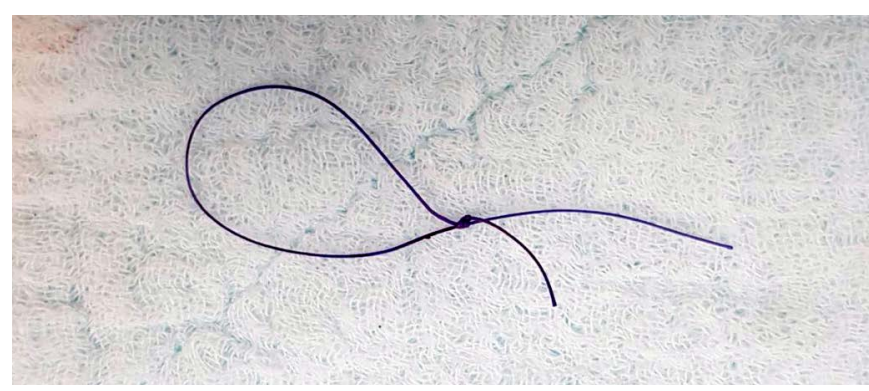

Figure 1. Loop prepared with the sailor's knot method.

\section{Surgical Approach}

All patients operated in our clinic underwent LA with the classical 3-port method. Foley catheter was used in all patients. A $10 \mathrm{~mm}$ camera trocar was inserted from the umbilicus with the open method and the pneumoperitoneum was created. $5 \mathrm{~mm}$ trocars were placed in the left lower quadrant and suprapubically. After the appendix was observed and appendectomy was diagnosed, appendiceal meso and artery were sealed and cut with laparoscopic energy devices. Loops were prepared outside the abdomen with $2 / 0$ vicryl and sailor's knot method in order to close the appendix stump in the patients in Group 1. In the prepared loop, the fixed end was left short and the end to be drawn to be squeezed intracorporeally was left long.

The loop prepared was sent from the suprapubic trocar into the abdomen by laparoscopic needle holder. It was passed through the loop by entering from the trocar in the lower left quadrant with the laparoscopic holder. Then, the appendix was held at the tip and the loop was placed on the appendix root. The appendix root was tied by holding the long end of the loop and tightening it appropriately. Second and third nodes were inserted in the same way. The appendix was cut with scissors from between the second and third sutures. The appendix root was cauterized. The appendix was taken out of the abdomen with a specimen bag. The same method was performed with the intracorporeal knot-tying method in Group 2 patients.

\section{Statistical Analysis}

The SPSS (Statistical Package for the Social Sciences) Version 16 statistical program (SPSS ${ }^{\circledR}$ Inc, Chicago, IL, USA) was used for the statistical analysis. The numerical data were presented as mean \pm standard deviation. The OneSample Kolmogorov Smirnov test was used to evaluate whether the numerical data conform to normal distribution. The Independent-Samples $\mathrm{T}$ test was used in the evaluation of the numerical data with normal distribution. We use Mann-Whitney U test with anormal distribution. The 
Pearson Chi-Square test and Fisher's Exact Test was used in the evaluation of the non-numerical data. Those with a p-value lower than 0.05 were accepted to be significant.

\section{Results}

Of the 47 patients included in the study, 24 (51\%) were male and 23 (\%49) were female. In Group 1, 15 (55.5\%) patients were male and $12(44.5 \%)$ patients were female. In Group 2, however, 9 (45\%) patients were male and 11 $(55 \%)$ patients were female (Table 1$)$. There was not different as gender in both group $(\mathrm{p}=0.474)$. The mean age of the patients in Group 1 was $33.70 \pm 13.43$ years. The mean age of the patients in Group 2 was $32.35 \pm 12.69$ years $(\mathrm{p}=0.728)$.

The mean length hospitalization of the patients in Group 1 was $3 \pm 1.68$ days, while it was $2.95 \pm 1.13$ days in Group 2 . The duration of surgery was $73.70 \pm 31.76$ minutes in Group 1 , while it was $70.75 \pm 27.25$ minutes in Group 2. There was

Table 1. Distribution of the group according to gender

\begin{tabular}{lccc} 
Gender & Group 1 & Group 2 & n \\
\hline Male & 15 & 9 & 24 \\
Female & 12 & 11 & 23 \\
Total & 27 & 20 & 47
\end{tabular}

Table 2. Patient characteristics in the groups

\begin{tabular}{|c|c|c|c|}
\hline & Group 1 & Group 2 & $\mathbf{p}$ \\
\hline Age & $33.70 \pm 13.43$ & $32.35 \pm 12.69$ & 0.728 \\
\hline $\begin{array}{l}\text { Duration of } \\
\text { surgery }\end{array}$ & & & \\
\hline (minute) & $73.70 \pm 31.76$ & $70.75 \pm 27.25$ & 0.734 \\
\hline $\begin{array}{l}\text { Length of } \\
\text { hospitalization } \\
\text { (day) }\end{array}$ & $3 \pm 1.68$ & $2.95 \pm 1.13$ & 0.915 \\
\hline
\end{tabular}

Table 3. Evaluation of the patients according to pathology results

\begin{tabular}{lccc} 
Appendix pathology & Group 1 & Group 2 & Total \\
\hline Catarrhal stage & 15 & 8 & 23 \\
Gangrenous & 3 & 1 & 4 \\
Phlegmonous & 3 & 1 & 4 \\
$\begin{array}{l}\text { Perforated } \\
\text { Reactive lymphoid }\end{array}$ & 3 & 6 & 9 \\
hyperplasia & 3 & 4 & 7 \\
\hline
\end{tabular}

no statistically significant difference between the two groups in terms of length of hospitalization and duration of surgery (Table 2). Trocar site infection developed in 3 patients in Group 1 and 2 patients in Group 2 ( $\mathrm{p}=0.644)$. No postoperative stump leakage was seen in any of the patients. The pathology results of the patients revealed catarrhal appendicitis in 23 patients, phlegmonous appendicitis in 4 patients, gangrenous appendicitis in 4 patients and perforated appendicitis in 9 patients. As a result of the pathological examination of the appendix material, 7 patients were reported to have reactive lymphoid hyperplasia. The distribution of pathology results by groups is shown in detail in Table 3 .

\section{Discussion}

Today, all kinds of gastrointestinal system surgeries can be performed by laparoscopic methods depending on the technological advancements. After the laparoscopic revolution in the last 40 years, LA has been widely accepted in most of the developed countries and is now a frequently preferred surgical method. ${ }^{[6]}$

Proper closure of the appendix stump during the LA procedure is important to prevent the development of postoperative complications. The methods used to close the stump in LA include staples, endoloop, titanium clips, non-absorbable polymer clips (hem-o-lock clips), handmade rings, extracorporeal slip knots, intracorporeal suturing as well as energy devices such as LigaSure or bipolar cautery. Studies on this subject have reported that all these methods are safe and applicable. ${ }^{[7-10]}$ However, many of these methods have been shown to be costly. ${ }^{[1]}$ To date, although studies are inadequate, it is reported that the appendix stump can be safely closed with handmade knots. ${ }^{[12,13]}$ The present study shows that the loop method prepared with intracorporeal and extracorporeal sailor's knots have the same level of safety. The appendix stump leak, which is considered as the most important morbidity of these methods, was not observed in any of our patients.

Although intracorporeal knot-tying is a basic skill in laparoscopic surgery, this method is sometimes seen as an important obstacle even by experienced surgeons in the field of laparoscopy. ${ }^{[14]}$ The most important advantage of stump closure with LA suture method is its low cost. However, one of the most important disadvantages of method is reported as the prolongation of the duration of surgery. In the study by Ay et al., ${ }^{[15]}$ the mean duration of surgery was 54 minutes in patients with complicated AA who un- 
derwent laparoscopic appendectomy with the intracorporeal knot-tying method and 40 minutes in uncomplicated AA patients and the difference between these durations was reported as statistically significant. In the present study, the duration of surgery was $70.75 \pm 27.25$ in Group 1 and 73.70 \pm 31.76 minutes in Group 2, and no difference was found between the methods used in terms of duration of surgery. The reason for this is that the number of cases included in the study is limited and that the patients are divided as complicated and non-complicated.

In the study by Kiudelis et al., ${ }^{[16]}$ intracorporeal ligation and endoloop ligation methods performed by experienced surgeons were compared and although a statistically significant difference was found in terms of duration of surgery, there was no statistically significant difference in terms of length of hospital stay, postoperative complication.

In the study by Katsuno et al., ${ }^{[17]}$ wound site infection was found in $6.4 \%$, intraabdominal abscess in $4.3 \%$, and small intestinal obstruction in $2.1 \%$ of patients. No intraabdominal abscess was observed in any of the patients included in the present study. A total of $5(10.6 \%)$ patients, with 3 (11.1\%) patients in Group 1 and $2(10 \%)$ patients in Group 2 , had wound site infection. The result was not found statistically significant.

In conclusion; it is an easy, reliable and cost-effective method to close the appendix stump by hand-made sailor' knot method in patients undergoing LA. The method can be used safely when intracorporeal knot-tying and suture cannot be performed.

\section{Acknowledgments}

This study was presented as an oral presentation at the $14^{\text {th }}$ endoscopic laparoscopic surgery congress.

\section{Disclosures}

Ethichs Committee Approval: The study was approved by the Local Ethics Committee.

Peer-review: Externally peer-reviewed.

Conflict of Interest: None declared.

\section{References}

1. Anderson JE, Bickler SW, Chang DC, Talamini MA. Examining a common disease with unknown etiology: trends in epidemiology and surgical management of appendicitis in California, 1995-2009. World J Surg 2012;36:2787-94.

2. McBurney C. IV. The Incision Made in the Abdominal Wall in
Cases of Appendicitis, with a Description of a New Method of Operating. Ann Surg 1894;20:38-43.

3. Semm K. Endoscopic appendectomy. Endoscopy. 1983;15:59-64.

4. Huber T, Paschold M, Bartsch F, Lang H, Kneist W. Appendectomy in surgical residency. What has changed over the past 10 years?. Chirurg 2016;87:326-31 [Article in German].

5. Mayir B, Ensari CÖ, Bilecik T, Aslaner A, Oruç MT. Methods for closure of appendix stump during laparoscopic appendectomy procedure. Ulus Cerrahi Derg 2015;31:229-31.

6. Dingemann J, Metzelder ML, Szavay PO. Current status of laparoscopic appendectomy in children: a nation wide survey in Germany. Eur J Pediatr Surg 2013;23:226-33.

7. Ates M, Dirican A, Ince V, Ara C, Isik B, Yilmaz S. Comparison of intracorporeal knot-tying suture (polyglactin) and titanium endoclips in laparoscopic appendiceal stump closure: a prospective randomized study. Surg Laparosc Endosc Percutan Tech 2012;22:226-31.

8. Sajid MS, Rimple J, Cheek E, Baig MK. Use of endo-GIA versus endo-loop for securing the appendicular stump in laparoscopic appendicectomy: a systematic review. Surg Laparosc Endosc Percutan Tech 2009;19:11-5.

9. Kazemier G, in't Hof KH, Saad S, Bonjer HJ, Sauerland S. Securing the appendiceal stump in laparoscopic appendectomy: evidence for routine stapling? Surg Endosc 2006;20:1473-6.

10. Gozeneli O, Tatli F, Yucel Y, Ozgonul A, Uzunkoy A. Can ultrasonic surgical devices be used to close the appendicular stump? Ann Ital Chir 2017;88:562-6.

11. McGrath B, Buckius MT, Grim R, Bell T, Ahuja V. Economics of appendicitis: cost trend analysis of laparoscopic versus open appendectomy from 1998 to 2008. J Surg Res 2011;171:e161-8.

12. Gomes CA, Nunes TA, Soares C Jr, Gomes CC. The appendiceal stump closure during laparoscopy: historical, surgical, and future perspectives. Surg Laparosc Endosc Percutan Tech 2012;22:1-4.

13. Yıldız I, Koca S. Is There An Ideal Stump Closure Technique In Laparoscopic Appendectomy? Surg Technol Int 2016;28:117-20.

14. Fuchs Weizman N, Maurer RMA, Einarsson Jl, Vitonis AF, Cohen SL. Survey on Barriers to Adoption of Laparoscopic Surgery. Journal of Minimally Invasive Gynecology 2014;21:S46.

15. Ay N, Dinç B, Alp V, Kaya Ş, Sevük U. Comparison of outcomes of laparoscopic intracorporeal knotting technique in patients with complicated and noncomplicated acute appendicitis. Ther Clin Risk Manag 2015;11:1213-6.

16. Kiudelis $M$, Ignatavicius $P$, Zviniene K, Grizas S. Analysis of intracorporeal knotting with invaginating suture versus endoloops in appendiceal stump closure. Wideochir Inne Tech Maloinwazyjne 2013;8:69-73.

17. Katsuno G, Nagakari K, Yoshikawa S, Sugiyama K, Fukunaga M. Laparoscopic appendectomy for complicated appendicitis: a comparison with open appendectomy. World J Surg 2009;33:208-14. 